\title{
Propofol versus Midazolam in Medical Thoracoscopy: A Randomized, Noninferiority Trial
}

\author{
Peter Grendelmeier Michael Tamm Kathleen Jahn Eric Pflimlin Daiana Stolz \\ Clinic of Pulmonary Medicine and Respiratory Cell Research, University Hospital Basel, Basel, Switzerland
}

\section{Key Words}

Medical thoracoscopy $\cdot$ Sedation $\cdot$ Propofol $\cdot$ Midazolam .

Risk $\cdot$ Procedure $\cdot$ Respiratory intervention

\begin{abstract}
Background: Hypoxemia is a surrogate marker for periprocedural endoscopic complications. There are no data comparing the safety of propofol sedation with another sedative regimen in medical thoracoscopy. Objective: To evaluate whether sedation with propofol is as safe and effective as sedation with midazolam. Methods: Ninety consecutive patients undergoing medical thoracoscopy were randomly allocated to receive either intravenous propofol or midazolam. Predefined periprocedural complications included hypoxemia, hypotension, bleeding, need for airway insertion, mechanical ventilation, intensive care unit transfer and death. The primary endpoint was the mean lowest oxygen saturation during the procedure. Results: Randomized groups had similar demographics (64 \pm 16 years, 57\% male, 91\% American Society of Anesthesiologists class III-IV) and a balanced distribution of procedures. The mean lowest oxygen saturation during the procedure was significantly lower in the propofol group as compared to the midazolam group ( $93 \pm 6$ vs. $96 \pm 3 \%, p=0.007$ ). Patients randomized to pro-
\end{abstract}

pofol showed more episodes of hypoxemia ( 27 vs. $4 \%, \mathrm{p}=$ 0.007 ) and hypotension ( 82 vs. $40 \%, p<0.0001$ ). No procedure had to be aborted. None of the patients required an artificial airway, mechanical ventilation or intensive care unit care, and none died. Conclusions: As assessed by the surrogate marker hypoxemia, propofol should not be considered the first choice for sedation in medical thoracoscopy.

(c) 2014 S. Karger AG, Base

\section{Introduction}

The first thoracoscopy was performed under local anesthesia by a Swedish internist more than a century ago [1]. In the early 1990s, the term 'medical thoracoscopy' was introduced, to distinguish the conventional technique from 'video-assisted thoracoscopic surgery' (VATS) $[2,3]$. While VATS requires general anesthesia and double-lumen tracheal intubation, medical thoracoscopy is performed using local anesthesia combined with sedation $[2,4]$.

For analgesia, fentanyl [5-8], morphine [9], sufentanil [10] and remifentanil infusion [10] have been used. Sedation is usually achieved by the oral or intravenous administration of midazolam $[5,10,11]$, diazepam [9] or pro-

\section{KARGER}

E-Mail karger@karger.com

www.karger.com/res
C 2014 S. Karger AG, Basel

0025-7931/14/0882-0126\$39.50/0
Prof. MPH Dr. med. Daiana Stolz

Clinic of Pulmonary Medicine and Respiratory Cell Research

University Hospital Basel, Petersgraben 4

CH-4031 Basel (Switzerland)

E-Mail daiana.stolz@usb.ch 
pofol [5-8]. Propofol (2,6-diisopropylphenol) is a sedative-hypnotic frequently used in the induction and maintenance of anesthesia. It has been extensively shown that sedation with propofol can be safely performed by a non-anesthesiologist during bronchoscopy [12-16]. Conversely, there are scarce data comparing the safety of different regimens of sedation for medical thoracoscopy $[17,18]$. Indeed, endoscopic procedures also have a small but definite risk of sedation-related complications [19, 20]. Hypoxemia has been shown to trigger myocardial ischemia during endoscopy in individuals with and without previous cardiac history and can eventually lead to neurological damage and death [21-23]. Due to the intuitive and straight relation between hypoxemia and adverse events as well as the rarity of severe complications during endoscopy, hypoxemia has been used as a surrogate for main periprocedural cardiopulmonary events $[24,25]$.

This prospective, single-center, randomized, noninferiority, controlled trial was designed to compare propofol and midazolam for sedation in medical thoracoscopy. The mean lowest oxygen saturation during the procedure was used as the primary endpoint.

\section{Methods}

\section{Patients}

Consecutive patients undergoing medical thoracoscopy between April 2011 and July 2012 in the tertiary care, 758-bed University Hospital Basel, Switzerland, were included in this trial and randomly allocated to receive either intravenous propofol or midazolam.

Inclusion criteria were as follows: indication for diagnostic or therapeutic thoracoscopy and age 18 years or older. Intubated or isolated patients, patients with a known allergy or intolerance to propofol or midazolam, pregnant or breast-feeding women and patients with a mental disorder preventing appropriate judgment concerning study participation were not included in the study. The study conformed to the Declaration of Helsinki. The study was approved by the institutional review board, Ethikkommission beider Basel (EKBB 151/11). Informed consent was obtained from each patient. The trial was registered with the Current Controlled Trials Database (ISRCTN 95930113).

All patients were assessed by a physician and a member of the nursing team trained in anesthesiology prior to the procedure, which included gradation of physical status in accordance with the American Society of Anesthesiologists (ASA) criteria. Current medications, such as anticoagulants, antiplatelet drugs, sedatives and hypnotics, were recorded. Comorbidities, including chronic obstructive pulmonary disease, coronary artery disease, congestive heart failure, cerebrovascular disease, renal failure, liver disease, malignant solid tumor, hematological malignancy, rheumatic disease, diabetes mellitus, alcohol abuse and HIV infection, were noted, and current blood work results were listed.
Patients were randomly assigned to either propofol or midazolam. A research nurse carried out every patient's assignment in the waiting room of the thoracoscopy suite. Randomization was done through arbitrary allocation to one of the two treatment groups based on a computer-generated random list (GraphPad Software, San Diego, Calif., USA).

\section{Thoracoscopy Course and Sedation Schemata}

Thoracoscopy was performed in the thoracoscopy suite by a total of 4 pulmonary attending physicians and 8 pulmonary fellows with the patient in the lateral decubitus position and the normal lung down. Fluoroscopy was performed following the artificial creation of a pneumothorax through a previously inserted chest tube. In the case of pleural effusion without previous insertion of a chest tube, the site of insertion of the trocar was identified after sonographic evaluation [26]. The trocar was usually inserted in the 6 th or 7 th intercostal space in the midaxillary line, unless there was a more appropriate site as seen on fluoroscopy or sonography.

All patients received $4 \mathrm{mg}$ of hydrocodone intravenously before sedation with propofol or midazolam was started. Local anesthesia ( $1 \%$ lidocaine) was performed by infiltration of the skin, the intercostal muscles and the pleura at the site of insertion of the trocar. A single $10-\mathrm{mm}$ trocar was inserted after a 1 - to $2-\mathrm{cm}$ incision and blunt preparation of the access to the pleural space. Thoracoscopy was performed using a $7-\mathrm{mm}$ rigid telescope.

If clinically indicated, pleural biopsies were obtained with a biopsy forceps. In the case of diffuse inflammation, biopsies were taken against the ribs to avoid injury to the intercostal vessels. When present, biopsies of nodules and masses were taken.

In the case of talc pleurodesis, dedicated calibrated and sterile talc was insufflated through the working channel under direct vision onto all pleural surfaces in a systematic manner from the diaphragm anteriorly to the apex and back down to the diaphragm posteriorly [27]. Talc was prepared in vials containing $3 \mathrm{~g}$ of talc each. For talc pleurodesis for pneumothorax, 1 vial was used, while for pleurodesis for malignant pleural effusion, 2 vials were insufflated.

A single chest tube was inserted. In the case of pleural effusion, empyema or talc pleurodesis it was placed in a dependent position. It was placed in an apical position in the case of pneumothorax. The chest tube was fixed and connected to a water-seal system. A negative pressure of $-20 \mathrm{~cm} \mathrm{H}_{2} \mathrm{O}$ was applied. The chest tube was left in place until the output decreased to less than $150 \mathrm{ml}$ per day in the absence of a persistent air leak. In the case of talc pleurodesis, the chest tube was left in place for at least $48 \mathrm{~h}$.

Midazolam was titrated as previously described [14]. Sedation was achieved initially with $2 \mathrm{mg}$ of midazolam and followed by further 1- to 2-mg intravenous midazolam boluses at the physician's discretion to achieve deep sedation as defined by the ASA. The dose of midazolam during the procedure was titrated to maintain sedation, i.e. induce an altered state of consciousness that minimizes pain and discomfort but still permits a patient to maintain an unassisted airway.

Patients assigned to the propofol group received an initial bolus of $10 \mathrm{mg}$ of intravenous propofol, immediately followed by the continuous infusion of propofol at an initial rate of $0.3 \mathrm{mg} / \mathrm{kg} / \mathrm{min}$, as previously described [28]. If adequate sedation was achieved, the infusion rate was reduced to $0.2 \mathrm{mg} / \mathrm{kg} / \mathrm{min}$ after $3 \mathrm{~min}$ and was further reduced to 0.1 and $0.05 \mathrm{mg} / \mathrm{kg} / \mathrm{min}$ after another 3 and 6 $\mathrm{min}$, respectively. In the case of inadequate sedation, a bolus of 10 
mg of propofol was given and the infusion rate was increased in reversed order to a maximum rate of $0.5 \mathrm{mg} / \mathrm{kg} / \mathrm{min}$. In the case of apnea, hypoxemia or hypotension, the continuous infusion could be reduced in the above-mentioned manner or completely stopped at any time as judged by the physician and endoscopy team performing the thoracoscopy. Sedation was administered by the endoscopy nurse at the performing physician's discretion. Patients were monitored by pulse oximetry, blood pressure measurements at defined intervals and electrocardiographic monitoring. Spurious readings caused by an inadequate signal were removed from the data.

For additional analgesia, patients received a total of $50 \mathrm{mg}$ of pethidine intravenously. A first dose of $25 \mathrm{mg}$ was given before preparation of the access site and a second bolus before insertion of the telescope through the trocar. In the case of talc pleurodesis, a total of $100 \mathrm{mg}$ of pethidine was regularly administered at the physician's discretion.

The total doses of propofol and midazolam were documented for each patient. Hemodynamic parameters, duration of thoracoscopy, indication, procedures and complications were noted during the procedure on a form specifically designed for the study. Diagnostic and therapeutic procedures, i.e. pleural biopsy, talc pleurodesis and adhesiolysis, were performed dependent upon the clinical indication.

\section{Outcome Parameters}

Hemodynamic monitoring was performed immediately before, during and shortly after the procedure and before transfer from the thoracoscopy suite to the ward. Electrocardiogram, pulse oximetry results and respiratory rate were recorded continuously during the procedure, and automated noninvasive blood pressure monitoring was performed every $5 \mathrm{~min}$. Supplemental oxygen was offered at 4 liters/min via a nasal cannula to all patients. In the case of desaturation to $<90 \%$, oxygen delivery was increased by steps of 2 liters/min.

Periprocedural complications were defined as uncontrollable cough, uncontrollable pain, oxygen desaturation $\leq 90 \%$, need for nasopharyngeal or oropharyngeal airway insertion, need for intubation, hypotension with a systolic blood pressure of $<90 \mathrm{~mm} \mathrm{Hg}$, minor or major bleeding, intensive care unit need, need to abort the thoracoscopy and death.

At the end of the procedure, the thoracoscopist charted their perception of cough during the procedure on a $10-\mathrm{cm}$ visual analogue scale $[14,29]$. Similarly, $24 \mathrm{~h}$ after thoracoscopy, patients were asked to record their discomfort, willingness to undergo a repeated procedure and fear of undergoing a repeated procedure on a $10-\mathrm{cm}$ visual analogue scale. On this scale, 0 denoted no discomfort, willingness or fear, while 10 represented great discomfort, willingness or fear of repeating the procedure.

Postprocedural complications were defined as uncontrollable pain, drain site infection, empyema, pleurocutaneous fistula, need for intubation, bleeding, intensive care unit need, need for insertion of an additional chest tube, need for rethoracoscopy and death. Patients were followed for up to 28 days after thoracoscopy.

\section{Endpoints}

The primary endpoint was the mean lowest oxygen saturation during the procedure.

Secondary predefined endpoints included the following: duration of the procedure; mean lowest breathing rate during the pro- cedure; mean lowest systolic blood pressure during the procedure; number (percentage) of complications during the procedure as assessed by the study physician during the procedure; number (percentage) of complications following the procedure as assessed by the study physician up to 28 days after the intervention; total dose of propofol and midazolam, respectively; dose of propofol and midazolam per kilogram body weight; dose of propofol and midazolam per kilogram body weight and per minute; total doses of hydrocodone and pethidine (meperidine); cough scores, as assessed on a visual analogue scale by nurses and physicians during the procedure; patient discomfort $24 \mathrm{~h}$ after the procedure; patient willingness to undergo a repeated procedure, assessed on a visual analogue scale $24 \mathrm{~h}$ after the procedure, and patient fear of undergoing a repeated procedure, as assessed on a visual analogue scale $24 \mathrm{~h}$ after the procedure.

\section{Data Analyses}

The primary objective of this trial was to show that for sedation in medical thoracoscopy the use of propofol via a continuous infusion was associated with a mean lowest saturation within $2 \%$ of that of the combination of midazolam and hydrocodone, or better, with $80 \%$ power using a one-sided statistical test with an a level of 0.05 . Assuming a mean lowest saturation of $94.8 \%$ with a standard deviation of $2.7 \%$ in the arm treated with the combination of midazolam and hydrocodone, a total of 80 patients were considered to be needed. Assuming a 5\% loss to follow-up, we aimed for a sample size of 90 patients, 45 in each treatment arm [30].

Differences in dichotomous variables were evaluated using the $\chi^{2}$ test or Fisher's exact test, as appropriate. Normally distributed parameters were analyzed using Student's t test for equality of means. All other continuously nonnormally distributed parameters were evaluated using the nonparametric Mann-Whitney $U$ test or Kruskal-Wallis test, as appropriate.

The difference in arterial oxygen saturation change between the randomized groups, taking into account the initial arterial oxygen saturation, was analyzed using a general linear model of repeated measures [30].

The Statistical Package for Social Sciences (SPSS Inc., version 21 for Windows) program was used. All tests are two-tailed; a $\mathrm{p}$ value of $<0.05$ was considered significant. Results are expressed as means (standard deviation) or medians (interquartile range), unless otherwise stated.

\section{Results}

Ninety consecutive patients undergoing medical thoracoscopy were included in this trial (fig. 1). Demographic data are presented in table 1. Randomization groups were well matched. Of note, more than $90 \%$ of all patients were classified as ASA III or higher and thus presented poor overall physical health.

Table 2 shows the indications as well as the number and distribution of procedures per patient and randomization group. The main indications for thoracoscopy were unclear pleural effusion and talc pleurodesis for proven malignant effusion ( $30 \%$ each). Pleural biopsy 
Fig. 1. CONSORT study flow chart for patients included in the study.

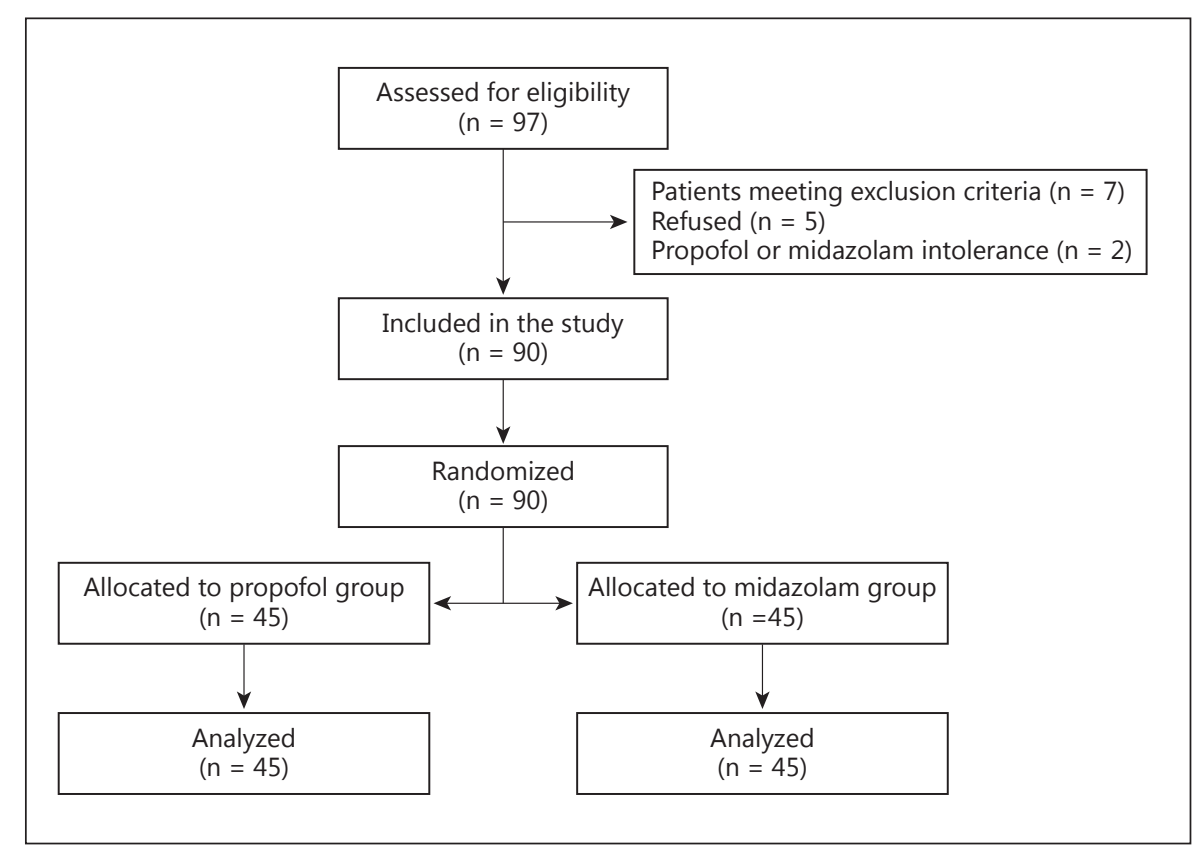

and talc pleurodesis were performed in 40 patients (44\%) and 46 patients (51\%), respectively. Involvement of the contralateral hemithorax at the moment of thoracoscopy could be detected radiologically in 11 patients ( 7 patients in the propofol group, 4 patients in the midazolam group).

\section{Primary Endpoint}

The mean lowest oxygen saturation during the procedure was significantly lower in the propofol group (93 \pm $6 \%$ in propofol group vs. $96 \pm 3 \%$ in midazolam group, $\mathrm{p}=0.007)$. Similarly, the lowest oxygen saturation at 3,6 and $9 \mathrm{~min}$ following initiation of sedation was significantly lower in the propofol group as compared to the midazolam group ( $96 \pm 5$ vs. $98 \pm 4 \%, \mathrm{p}=0.035 ; 97 \pm 4$ vs. $98 \pm 2 \%, \mathrm{p}=0.033 ; 97 \pm 4$ vs. $98 \pm 2 \%, \mathrm{p}=0.023)$.

\section{Secondary Endpoints}

Hemodynamic Parameters

Table 3 presents the hemodynamic findings before, during and after thoracoscopy. Details of peri- and postinterventional adverse events are shown in table 4 . Hypoxemia, defined as an oxygen saturation $\leq 90 \%$, was seen in 14 patients (16\%). It was significantly more frequent in the propofol group compared to the midazolam group $(\mathrm{p}=0.007)$. Notably, randomization group remained an independent predictor of hypoxemia in a logistic multivariate regression including age, gender and systolic blood pressure when arriving at the thoracoscopy suite (OR 0.159, 95\% CI 0.031-0.828, $\mathrm{p}=0.029$ ).

The lowest respiratory rate was significantly decreased in the propofol group [11 (9-14) vs. 14 (13-16) breaths/ $\min , \mathrm{p}=0.002]$ as compared to the midazolam group. Conversely, there was no significant difference between the two groups with regard to lowest or highest heart rate.

Hypotension, defined as a systolic pressure $<90 \mathrm{~mm}$ $\mathrm{Hg}$, was seen in 55 patients (61\%). It was significantly more frequently encountered in the propofol group (82 vs. $40 \%, \mathrm{p}<0.0001)$. In a logistic multivariate regression analysis, randomization group remained an independent predictor of hypotension when adjusted for gender, systolic blood pressure when arriving at the thoracoscopy suite and pethidine dose (OR 0.082, 95\% CI 0.023-0.295, $\mathrm{p}<0.0001$ ).

The lowest systolic and diastolic blood pressure (82 vs. $95 \mathrm{~mm} \mathrm{Hg}, \mathrm{p}<0.00001$, and 46 vs. $53 \mathrm{~mm} \mathrm{Hg}, \mathrm{p}=0.008$, respectively) as well as systolic and diastolic blood pressure at the end of the procedure (93 vs. $109 \mathrm{~mm} \mathrm{Hg}, \mathrm{p}<$ 0.0001 , and 54 vs. $65 \mathrm{~mm} \mathrm{Hg}, \mathrm{p}=0.001$, respectively) were significantly lower in the propofol group.

Overall, lowest oxygen saturation for patients with previous insertion of a chest tube was $93.9 \pm 5.1 \%$ as compared to $94.6 \pm 4.5 \%$ for patients without previous insertion of a chest tube, i.e. direct insertion of the trocar under sonographic guidance $(\mathrm{p}=0.466)$. Corresponding 
Table 1. Demographic data of 90 consecutive patients undergoing medical thoracoscopy

\begin{tabular}{|c|c|c|c|c|}
\hline Characteristic & $\begin{array}{l}\text { Propofol } \\
(\mathrm{n}=45)\end{array}$ & $\begin{array}{l}\text { Midazolam } \\
(\mathrm{n}=45)\end{array}$ & $\begin{array}{l}\text { Total } \\
(\mathrm{n}=90)\end{array}$ & $\mathrm{p}$ value \\
\hline Age, years & $65 \pm 16$ & $63 \pm 16$ & $64 \pm 16$ & 0.517 \\
\hline Male & $21(46.7 \%)$ & $30(66.7 \%)$ & $51(56.7 \%)$ & 0.056 \\
\hline Height, cm & $169 \pm 9$ & $172 \pm 10$ & $171 \pm 10$ & 0.116 \\
\hline Weight, kg & $68 \pm 15$ & $69 \pm 13$ & $68 \pm 14$ & 0.498 \\
\hline BMI & $24 \pm 4$ & $23 \pm 3$ & $23 \pm 4$ & 0.819 \\
\hline \multicolumn{5}{|l|}{ Smoking status } \\
\hline Never smoker & $20(44.4 \%)$ & $12(26.7 \%)$ & $32(35.6 \%)$ & \multirow{3}{*}{0.158} \\
\hline Current smoker & $6(13.3 \%)$ & $11(24.4 \%)$ & $17(18.9 \%)$ & \\
\hline Ex-smoker & $19(42.2 \%)$ & $22(48.9 \%)$ & $41(45.6 \%)$ & \\
\hline \multicolumn{5}{|l|}{ ASA class } \\
\hline I & $0(0 \%)$ & $0(0 \%)$ & $0(0 \%)$ & \multirow[t]{4}{*}{0.757} \\
\hline II & $3(7 \%)$ & $5(11 \%)$ & $8(9 \%)$ & \\
\hline III & $40(89 \%)$ & $38(85 \%)$ & $78(87 \%)$ & \\
\hline IV or $\mathrm{V}$ & $2(4 \%)$ & $2(4 \%)$ & $4(4 \%)$ & \\
\hline \multicolumn{5}{|l|}{ Comorbidities } \\
\hline COPD & $7(16 \%)$ & $11(24 \%)$ & $18(20 \%)$ & 0.430 \\
\hline Coronary artery disease & $5(11 \%)$ & $10(22 \%)$ & $15(17 \%)$ & 0.258 \\
\hline Congestive heart failure & $5(11 \%)$ & $2(4 \%)$ & $7(8 \%)$ & 0.434 \\
\hline Cerebral vascular disease & $0(0 \%)$ & $2(4 \%)$ & $2(2 \%)$ & 0.494 \\
\hline Diabetes mellitus & $4(9 \%)$ & $2(4 \%)$ & $6(7 \%)$ & 0.677 \\
\hline Renal failure & $2(4 \%)$ & $12(27 \%)$ & $14(16 \%)$ & 0.007 \\
\hline Liver disease & $3(7 \%)$ & $1(2 \%)$ & $4(4 \%)$ & 0.616 \\
\hline Solid malignant tumor & $27(60 \%)$ & $26(58 \%)$ & $53(59 \%)$ & 0.830 \\
\hline Hematological malignancy & $6(13 \%)$ & $3(7 \%)$ & $9(10 \%)$ & 0.485 \\
\hline Immunosuppression & $4(9 \%)$ & $2(4 \%)$ & $6(7 \%)$ & 0.677 \\
\hline Rheumatologic disease & $2(4 \%)$ & $1(2 \%)$ & $3(3 \%)$ & 1.000 \\
\hline HIV & $0(0 \%)$ & $0(0 \%)$ & $0(0 \%)$ & 1.000 \\
\hline Alcohol abuse & $4(9 \%)$ & $4(9 \%)$ & $8(9 \%)$ & 1.000 \\
\hline Intravenous drug use & $1(2 \%)$ & $0(0 \%)$ & $1(1 \%)$ & 1.000 \\
\hline \multicolumn{5}{|l|}{ Current medication } \\
\hline Acetylsalicylic acid & $8(18 \%)$ & $12(27 \%)$ & $20(22 \%)$ & 0.310 \\
\hline Clopidogrel & $0(0 \%)$ & $1(2 \%)$ & $1(1 \%)$ & 1.000 \\
\hline Prasugrel & $0(0 \%)$ & $1(2 \%)$ & $1(1 \%)$ & 1.000 \\
\hline Oral anticoagulant & $1(2 \%)$ & $3(7 \%)$ & $4(4 \%)$ & 0.616 \\
\hline Heparin (therapeutic dose) & $0(0 \%)$ & $0(0 \%)$ & $0(0 \%)$ & 1.000 \\
\hline Heparin (prophylactic dose) & $1(2 \%)$ & $1(2 \%)$ & $2(2 \%)$ & 1.000 \\
\hline LMWH (therapeutic dose) & $0(0 \%)$ & $2(4 \%)$ & $2(2 \%)$ & 0.494 \\
\hline LMWH (prophylactic dose) & $23(51 \%)$ & $23(51 \%)$ & $46(51 \%)$ & 1.000 \\
\hline Sedatives & $1(2 \%)$ & $4(9 \%)$ & $5(6 \%)$ & 0.361 \\
\hline Hypnotics & $3(7 \%)$ & $5(11 \%)$ & $8(9 \%)$ & 0.714 \\
\hline Mean prothrombin time, $\%$ & $88.7 \pm 18.0$ & $91.2 \pm 15.7$ & $90 \pm 17$ & 0.403 \\
\hline Mean platelet count, $\times 10^{9} / 1$ & $367 \pm 194$ & $418 \pm 185$ & $388 \pm 187$ & 0.201 \\
\hline
\end{tabular}

Data are presented as means \pm SD or numbers of patients (percentage). BMI = Body mass index; COPD = chronic obstructive pulmonary disease; HIV = human immunodeficiency virus; LMWH = low-molecular-weight heparin. 
Table 2. Main indications for the examination and procedures per randomization group

\begin{tabular}{|c|c|c|c|c|}
\hline & $\begin{array}{l}\text { Propofol } \\
(\mathrm{n}=45)\end{array}$ & $\begin{array}{l}\text { Midazolam } \\
(\mathrm{n}=45)\end{array}$ & $\begin{array}{l}\text { Total } \\
(\mathrm{n}=90)\end{array}$ & $\mathrm{p}$ value \\
\hline \multicolumn{5}{|l|}{ Indication for thoracoscopy } \\
\hline \multicolumn{5}{|l|}{ Diagnostic thoracoscopy } \\
\hline Suspicion of malignancy & $9(20 \%)$ & $7(16 \%)$ & $16(18 \%)$ & 0.581 \\
\hline Pleural effusion of unclear etiology & $15(33 \%)$ & $12(27 \%)$ & $27(30 \%)$ & 0.490 \\
\hline \multicolumn{5}{|l|}{ Therapeutic thoracoscopy } \\
\hline Empyema & $4(9 \%)$ & $11(24 \%)$ & $15(17 \%)$ & 0.087 \\
\hline Talc pleurodesis for malignant effusion & $14(31 \%)$ & $13(29 \%)$ & $27(30 \%)$ & 0.818 \\
\hline Pneumothorax & $3(7 \%)$ & $2(4 \%)$ & $5(6 \%)$ & 1.000 \\
\hline \multicolumn{5}{|l|}{ Procedure performed } \\
\hline Pleural biopsy & $23(51 \%)$ & $17(38 \%)$ & $40(44 \%)$ & 0.203 \\
\hline Adhesiolysis & $10(22 \%)$ & $17(38 \%)$ & $27(30 \%)$ & 0.107 \\
\hline Talc pleurodesis & $25(56 \%)$ & $21(47 \%)$ & $46(51 \%)$ & 0.399 \\
\hline
\end{tabular}

Data are presented as numbers of patients (percentage). Due to rounding, percentages do not always add up to 100 .

figures were $94.8 \pm 3.4 \%(\mathrm{n}=25)$ and $96.5 \pm 2.2 \%(\mathrm{n}=$ $20 ; \mathrm{p}=0.063)$ for patients randomized to the midazolam group and $93.0 \pm 6.2 \%(\mathrm{n}=29)$ versus $92.4 \pm 5.5 \%(\mathrm{n}=$ $16 ; \mathrm{p}=0.724)$ for patients randomized to the propofol group.

\section{Other Complications}

There was no need to abort any intervention or for transfer to the intensive care unit. There were no deaths. VATS or thoracotomy were required in 9 cases (persisting pneumothorax in 2 , empyema in 5 , pleural effusion of unclear etiology in 2, $\mathrm{p}=$ not significant for all). Four patients (all in the propofol group) underwent repeat medical thoracoscopy for persisting malignant effusion after talc pleurodesis $(n=1)$ and pleural effusion of unclear etiology $(n=3)$.

\section{Medication Requirements}

Patients received a median dose of 310 (217-454) mg of propofol for the procedure. This dose corresponds to $4.69(3.19-6.52) \mathrm{mg} / \mathrm{kg}$ and $0.120(0.100-0.144) \mathrm{mg} / \mathrm{kg} /$ $\mathrm{min}$. Patients received a median dose of $9(6.5-13) \mathrm{mg}$ of midazolam for the procedure, corresponding to 0.13 $(0.10-0.16) \mathrm{mg} / \mathrm{kg}$ and $3(2-4) \mu \mathrm{g} / \mathrm{kg} / \mathrm{min}$. The propofol group required a significantly lower pethidine dose as compared to the midazolam group ( $45 \pm 25$ vs. $61 \pm 31$ $\mathrm{mg}, \mathrm{p}=0.008$; table 5).

\section{Duration}

There was no difference in the duration of the intervention between the groups ( $\mathrm{p}=0.881$; table 5$)$. In a linear multivariate regression analysis, the duration of the procedure was associated with the presence of empyema and performance of adhesiolysis but was independent of the group, the presence of pneumothorax or requirement for pleurodesis.

\section{Cough and Discomfort Scores}

Cough scores as judged by the thoracoscopists and patients themselves, the perception of discomfort, anxiety and fitness related to the procedure as well as readiness for repeat thoracoscopy did not differ between patients in the two treatment groups (table 6). Cough scores as judged by the nursing staff differed significantly between the two groups studied and were - although the difference was quite minor - significantly higher in the midazolam group. The correlation between the judgment of cough by the nursing staff and the thoracoscopist was only moderate $(\rho=0.567, \mathrm{p}<0.001)$.

\section{Discussion}

This is the first randomized study comparing two different sedation schemata for diagnostic and therapeutic medical thoracoscopy. Our results suggest that the mean lowest oxygen saturation is significantly lower in patients 
Table 3. Hemodynamic parameters per randomization group

\begin{tabular}{|c|c|c|c|c|c|c|c|}
\hline Characteristics & $\begin{array}{l}\text { Propofol } \\
(\mathrm{n}=45)\end{array}$ & $\begin{array}{l}\text { Midazolam } \\
(\mathrm{n}=45)\end{array}$ & $\begin{array}{l}\mathrm{p} \text { value } \\
(\mathrm{n}=90)\end{array}$ & Characteristics & $\begin{array}{l}\text { Propofol } \\
(\mathrm{n}=45)\end{array}$ & $\begin{array}{l}\text { Midazolam } \\
(\mathrm{n}=45)\end{array}$ & $\begin{array}{l}\mathrm{p} \text { value } \\
(\mathrm{n}=90)\end{array}$ \\
\hline \multicolumn{4}{|l|}{ At arrival in thoracoscopy suite } & \multicolumn{4}{|l|}{ At 9 min of sedation } \\
\hline Systolic BP, mm Hg & $131 \pm 28$ & $126 \pm 21$ & 0.346 & Systolic BP, mm Hg & $95 \pm 26$ & $105 \pm 1.7$ & 0.026 \\
\hline Diastolic BP, mm Hg & $71 \pm 14$ & $69 \pm 15$ & 0.438 & Diastolic BP, mm Hg & $56 \pm 21$ & $58 \pm 15$ & 0.463 \\
\hline Heart rate, bpm & $84 \pm 17$ & $86 \pm 16$ & 0.579 & Heart rate, bpm & $78 \pm 16$ & $80 \pm 16$ & 0.539 \\
\hline Respiratory rate, breaths/min & $19(16-24)$ & $16(15-23)$ & 0.546 & Respiratory rate, breaths/min & $17(14-20)$ & $18(13-23)$ & 0.457 \\
\hline Oxygen saturation, $\%$ & $94.4 \pm 4.2$ & $94.8 \pm 4.7$ & 0.676 & Oxygen saturation, $\%$ & $97 \pm 4$ & $98 \pm 2$ & 0.023 \\
\hline Amount of oxygen, liters & $0.8 \pm 1.6$ & $0.8 \pm 1.9$ & 0.856 & Amount of oxygen, liters & $4.5 \pm 2.3$ & $4.6 \pm 1.4$ & 0.880 \\
\hline \multicolumn{4}{|l|}{ At start of sedation } & \multicolumn{4}{|l|}{ At end of thoracoscopy } \\
\hline Systolic BP, mm Hg & $125 \pm 31$ & $119 \pm 18$ & 0.197 & Systolic BP, mm Hg & $93 \pm 20$ & $109 \pm 21$ & $<0.0001$ \\
\hline Diastolic BP, mm Hg & $67 \pm 15$ & $65 \pm 14$ & 0.461 & Diastolic BP, mm Hg & $54 \pm 13$ & $65 \pm 18$ & $<0.001$ \\
\hline Heart rate, bpm & $82 \pm 15$ & $83 \pm 17$ & 0.847 & Heart rate, bpm & $81 \pm 18$ & $87 \pm 18$ & 0.080 \\
\hline Respiratory rate, breaths/min & $19(14-26)$ & $18(16-22)$ & 0.505 & Respiratory rate, breaths/min & $17(12-23)$ & $18(16-24)$ & 0.154 \\
\hline Oxygen saturation, $\%$ & $97 \pm 3$ & $98 \pm 2$ & 0.437 & Oxygen saturation, $\%$ & $97 \pm 3$ & $97 \pm 3$ & 0.939 \\
\hline Amount of oxygen, liters & $4.3 \pm 1.3$ & $4.3 \pm 1.2$ & 0.730 & Amount of oxygen, liters & $4.2 \pm 3.2$ & $3.4 \pm 6.2$ & 0.479 \\
\hline \multicolumn{4}{|l|}{ At 3 min of sedation } & \multicolumn{4}{|l|}{ At 5 min after thoracoscopy } \\
\hline Systolic BP, mm Hg & $106 \pm 30$ & $110 \pm 21$ & 0.617 & Systolic BP, mm Hg & $96 \pm 21$ & $104 \pm 19$ & 0.038 \\
\hline Diastolic BP, mm Hg & $58 \pm 18$ & $61 \pm 15$ & 0.458 & Diastolic BP, mm Hg & $54 \pm 14$ & $61 \pm 16$ & 0.033 \\
\hline Heart rate, bpm & $80 \pm 15$ & $82 \pm 16$ & 0.614 & Heart rate, bpm & $83 \pm 19$ & $87 \pm 17$ & 0.268 \\
\hline Respiratory rate, breaths/min & $17(13-20)$ & $19(15-22)$ & 0.151 & Respiratory rate, breaths/min & $20(13-24)$ & $19(17-22)$ & 0.973 \\
\hline Oxygen saturation, $\%$ & $96 \pm 5$ & $98 \pm 4$ & 0.035 & Oxygen saturation, $\%$ & $96 \pm 3$ & $96 \pm 4$ & 0.441 \\
\hline Amount of oxygen, liters & $5.0 \pm 2.0$ & $4.4 \pm 1.2$ & 0.095 & Amount of oxygen, liters & $2.3 \pm 2.7$ & $2.2 \pm 2.8$ & 0.883 \\
\hline \multicolumn{4}{|l|}{ At 6 min of sedation } & \multicolumn{4}{|l|}{ Extreme values } \\
\hline Systolic BP, mm Hg & $99 \pm 28$ & $107 \pm 17$ & 0.082 & Lowest systolic BP, mm Hg & $82 \pm 18$ & $95 \pm 17$ & $<0.00001$ \\
\hline Diastolic BP, mm Hg & $56 \pm 21$ & $60 \pm 15$ & 0.302 & Lowest diastolic $\mathrm{BP}, \mathrm{mm} \mathrm{Hg}$ & $46 \pm 11$ & $53 \pm 14$ & 0.008 \\
\hline Heart rate, bpm & $79 \pm 17$ & $81 \pm 15$ & 0.621 & Lowest heart rate, bpm & $73 \pm 16$ & $77 \pm 16$ & 0.224 \\
\hline Respiratory rate, breaths/min & $17(15-21)$ & $19(16-22)$ & 0.290 & Highest heart rate, bpm & $90 \pm 16$ & $91 \pm 20$ & 0.802 \\
\hline Oxygen saturation, $\%$ & $97 \pm 4$ & $98 \pm 2$ & 0.033 & \multicolumn{4}{|l|}{ Lowest respiratory rate, } \\
\hline \multirow[t]{3}{*}{ Amount of oxygen, liters } & $4.5 \pm 2.3$ & $4.3 \pm 1.4$ & 0.723 & breaths/min & $11(9-14)$ & $14(13-16)$ & 0.001 \\
\hline & & & & Lowest oxygen saturation, \% & $93 \pm 6$ & $96 \pm 3$ & 0.007 \\
\hline & & & & $\begin{array}{l}\text { Highest amount of oxygen, } \\
\text { liter }\end{array}$ & $6.1 \pm 2.7$ & $5.4 \pm 2.0$ & \\
\hline
\end{tabular}

Data are presented as means $\pm \mathrm{SD}$ or medians (interquartile range). $\mathrm{BP}=$ Blood pressure.

receiving propofol as compared to patients receiving midazolam. Moreover, the percentage of patients presenting an oxygen saturation $\leq 90 \%$ and a systolic blood pressure $<90 \mathrm{~mm} \mathrm{Hg}$ was significantly higher in the propofol group. Thus, in contrast to flexible bronchoscopy $[14-16,29]$, propofol does not seem to be the drug of choice for sedation in medical thoracoscopy.

Traditionally, midazolam was used for sedation for bronchoscopy as well as medical thoracoscopy $[5,10]$. For the former, propofol has proved to be an attractive option to combined sedation with midazolam and hydrocodone, providing significantly faster recovery times and improved patient satisfaction scores $[14,15]$. The feasibil- ity and safety of propofol sedation as administered by a repeated bolus technique was also supported by two large cohort studies $[12,16]$. In contrast, reports on sedation for medical thoracoscopy, including its related adverse events, with midazolam, propofol or any other drug are scarce.

Gravino et al. [10] compared two protocols of analgosedation with either midazolam and sufentanil or midazolam and continuous remifentanil infusion in 65 patients undergoing talc pleurodesis. Hypotension (33.6 and $34.3 \%$ ) and hypoxemia (9 and 6.2\%) were the most common adverse events [10]. These findings are in agreement with our results, and the overall physical health of 
Table 4. Postprocedural and minor periprocedural adverse events per randomization group

\begin{tabular}{lcccc}
\hline & $\begin{array}{l}\text { Propofol } \\
(\mathrm{n}=45)\end{array}$ & $\begin{array}{l}\text { Midazolam } \\
(\mathrm{n}=45)\end{array}$ & $\begin{array}{l}\text { Total } \\
(\mathrm{n}=90)\end{array}$ & p value \\
\hline Periprocedural adverse events & & & & $<0.0001$ \\
Hypotension (systolic pressure $<90 \mathrm{~mm} \mathrm{Hg})$ & $37(82 \%)$ & $18(40 \%)$ & $55(61 \%)$ & 0.007 \\
Hypoxemia (oxygen saturation $\leq 90 \%)$ & $12(27 \%)$ & $2(4 \%)$ & $14(16 \%)$ & 0.118 \\
Chin lift & $9(20 \%)$ & $3(7 \%)$ & $12(13 \%)$ & 0.616 \\
Insertion of nasopharyngeal/oropharyngeal airway & $3(7 \%)$ & $1(2 \%)$ & $4(4 \%)$ & 1.000 \\
Uncontrollable cough & $0(0 \%)$ & $0(0 \%)$ & $0(0 \%)$ & 1.000 \\
Uncontrollable pain & $0(0 \%)$ & $0(0 \%)$ & $0(0 \%)$ & 0.616 \\
Minor bleeding & $1(2 \%)$ & $3(7 \%)$ & $4(4 \%)$ & 1.000 \\
Postprocedural adverse events & & & $0(0 \%)$ & 1.000 \\
Uncontrollable pain & $0(0 \%)$ & $0(0 \%)$ & $0(0 \%)$ & 1.000 \\
Empyema & $0(0 \%)$ & $0(0 \%)$ & $0(0 \%)$ & 1.000 \\
Pleurocutaneous fistula & $0(0 \%)$ & $0(0 \%)$ & $0(0 \%)$ & 1.000 \\
Bleeding & $0(0 \%)$ & $0(0 \%)$ & $6(7 \%)$ & 0.384 \\
Need for additional chest tube & $3(7 \%)$ & $3(7 \%)$ & $5(16 \%)$ & 1.000 \\
Need for reintervention & $9(20 \%)$ & $5(11 \%)$ & $5(6 \%)$ & \\
Death & $2(4 \%)$ & $3(7 \%)$ & & \\
\hline
\end{tabular}

Data are presented as numbers of patients (percentage).

Table 5. Thoracoscopy characteristics per randomization group

\begin{tabular}{|c|c|c|c|}
\hline Characteristic & $\begin{array}{l}\text { Propofol } \\
(\mathrm{n}=45)\end{array}$ & $\begin{array}{l}\text { Midazolam } \\
(\mathrm{n}=45)\end{array}$ & $\begin{array}{l}\mathrm{p} \\
\text { value }\end{array}$ \\
\hline Hydrocodone, mg & $4.44 \pm 1.75$ & $4.18 \pm 1.47$ & 0.436 \\
\hline Pethidine, mg & $45 \pm 25$ & $61 \pm 31$ & 0.008 \\
\hline Lidocaine, $\mathrm{ml}$ & $18.8 \pm 9.6$ & $18.5 \pm 3.1$ & 0.844 \\
\hline Position: right lateral decubitus & $20(44 \%)$ & $20(44 \%)$ & 1.000 \\
\hline \multicolumn{4}{|l|}{ Choice of trocar insertion site } \\
\hline By sonography & $16(36 \%)$ & $20(44 \%)$ & 0.389 \\
\hline By fluoroscopy & $29(64 \%)$ & $25(56 \%)$ & \\
\hline Duration of procedure, min & $38(31-50)$ & $39(32-52)$ & 0.881 \\
\hline
\end{tabular}

Data are presented as means $\pm \mathrm{SD}$, medians (interquartile range) or numbers of patients (percentage).

the patient population was comparable in both studies, with the vast majority of patients belonging to ASA classes III and IV. However, there were major differences in the analgosedation protocols applied in both studies, making a direct comparison of the data challenging. The amount of midazolam administered in the study of Gravino et al. [10] was almost 10 times less than the amount required in our trial. Notably, in the study by Gravino et al. [10], analgosedation was mainly achieved by an opiate (sufentanil or remifentanil). In contrast, in our study, hy-
Table 6. Outcome parameters per randomization group

\begin{tabular}{lcll}
\hline Characteristic & $\begin{array}{l}\text { Propofol } \\
(\mathrm{n}=45)\end{array}$ & $\begin{array}{l}\text { Midazolam } \\
(\mathrm{n}=45)\end{array}$ & $\mathrm{p}$ value \\
\hline $\begin{array}{l}\text { Cough score } \\
\quad \text { Physician VAS }\end{array}$ & $0(0-0)$ & $0(0-1)$ & 0.161 \\
$\quad$ Nurse VAS & $0(0-1)$ & $1(0-2)$ & 0.020 \\
$\quad$ Patient VAS & $1(0-3)$ & $1(0-3)$ & 0.934 \\
Discomfort score & $1(0.75-2.25)$ & $1(0-3)$ & 0.810 \\
Anxiety score & $2.5(0-4.25)$ & $3(0-6)$ & 0.679 \\
Fitness score & $5(4-7)$ & $5(4-7)$ & 0.967 \\
\hline
\end{tabular}

Data are presented as medians (interquartile range). $\mathrm{VAS}=\mathrm{Vi}-$ sual analogue scale.

drocodone was used only in a minor fixed dose due to its proven antitussive effect in respiratory interventions, as previously described [31]. Thus, it would be plausible to speculate that the higher dose of opiates used in the earlier study could account for the relatively higher incidence of hypotension and hypoxemia despite the much lower midazolam doses.

Chhajed et al. [11], investigating hypoventilation during medical thoracoscopy, reported a mean dose of midazolam of $5.7 \pm 3 \mathrm{mg}$ and a mean lowest oxygen satura- 
tion of $94.9 \pm 3.5 \%$, with 1 out of 14 patients $(7 \%)$ showing a fall in oxygen saturation to below $90 \%$. Even though the median dose of midazolam in the current study was substantially higher than in that report, the lowest oxygen saturation and the number of patients showing a desaturation were similar. In a study by Chen et al. [8] combining analgosedation using intravenous fentanyl and propofol with epidural anesthesia for nonintubated thoracoscopic lobectomy for lung cancer in 30 patients, the mean lowest oxygen saturation during surgery was $95.6 \pm 3.2 \%$. A comparison with our data is hampered by several reasons; in the study by Chen et al. [8], propofol doses were not reported, intravenous sedation was combined with peridural analgesia, only one fourth of their patients belonged to ASA class III, as compared to $75 \%$ of our population, and the mean values for dynamic and static pulmonary volumes were normal.

So far, Tschopp et al. [7] have provided the most detailed data about propofol sedation, in 53 patients undergoing medical thoracoscopy. Hypotension, as defined by a systolic arterial pressure of $<100 \mathrm{~mm} \mathrm{Hg}$ or a mean arterial pressure of $<60 \mathrm{~mm} \mathrm{Hg}$, was encountered in $34 \mathrm{pa}-$ tients (64.1\%). Hypoxemia (oxygen saturation of $<90 \%$ lasting at least $120 \mathrm{~s}$ ) was documented in 4 patients (7.6\%) [7]. Whereas the rate of hypotension was similar to the current results, more patients in our trial were observed to be hypoxemic at least once during the procedure. Nonetheless, a lower incidence of hypotension and a higher incidence of hypoxemia would have been observed in the former cohort if the present definitions were applied. Further potential explanations for the increased incidence of hypoxemia in our study include the diverging sedation regimens, longer median operating times and higher ASA scores. Accordingly, the median cumulative propofol dose in the study by Tschopp et al. [7] was 130 (20-410) $\mathrm{mg}$ as compared to $310(217-454) \mathrm{mg}$ in our patients. The higher propofol requirements are at least partially justified by the longer median operating time [ 28 $(9-112)$ vs. $38(31-50) \mathrm{min}]$ necessary to perform more complex procedures, particularly adhesiolysis for empyema, in the current cohort. Finally, fewer than $10 \%$ of the patients in the current study were classified as ASA I or II, while the vast majority of the patients (87\%) included in the study by Tschopp et al. [7] belonged to these two low-risk classes.

It is intriguing that propofol proved to provide a compelling safety profile for bronchoscopy sedation in several randomized, controlled trials, whereas it seems to be inferior to midazolam for thoracoscopy sedation. There are two possible explanations for this difference observed between patients undergoing bronchoscopy and thoracoscopy. Firstly, in contrast to patients undergoing thoracoscopy, patients undergoing bronchoscopy are being constantly stimulated by the scope at the level of the larynx, thereby increasing respiratory drive. Secondly, during thoracoscopy there might be an increased shunt effect by increased blood flow through the collapsed lung due to the vasodilatatory action of propofol.

Cough scores as judged by the nursing staff differed significantly between the two study groups. Conversely, cough scores were similar in the groups as judged by the thoracoscopists and patients themselves. The difference might be explained by the cough-suppressing effect of propofol. However, the perception of increased cough as assessed by the nursing staff was not reflected in higher cough suppressant requirements or a longer duration of the procedure. Nevertheless, cough scores were very low in the assessment of patients, physicians and nursing staff, both for the propofol and the midazolam group.

In this study, hydrocodone was routinely given to all patients in order to reduce the risk of lesions to the visceral pleura by the rigid thoracoscope in the case of coughing. As previously shown in two randomized studies, hydrocodone, both in combination with midazolam and propofol, markedly reduced cough during flexible bronchoscopy without causing significant desaturation $[29,31]$. Hydrocodone was preferred over other formulations due to its favorable cost profile as compared to the newer opiates [31].

There was no difference in lowest oxygen saturation in patients with and without pneumothorax induced prior to the thoracoscopy procedure itself and/or fluid at the start of thoracoscopy. This was true both for the cohort as a whole as well as for each randomized group. Thus, adaptation to the shunt produced by air and/or fluid prior to the intervention does not seem to be relevant for the development of peri-interventional hypoxemia.

The present study has a few limitations. The main one is the fact that we used hypoxemia as a surrogate marker for morbidity and mortality instead of peri-interventional mortality as the endpoint of the study. However, due to the rarity of lethal complications in this setting (0.05-1\%) $[1,32,33]$, the estimated sample size for a study identifying a difference in mortality of $0.5 \%$ between the groups would be over 15,000 patients. Even a composite endpoint including relevant complications (incidence less than 3\%) and tolerating a 2 -fold higher incidence of adverse events (6\%) would require over 1,500 patients. We assume that it is fair to state that if at all conceivable, such a large study would require several centers worldwide. 
Furthermore, such a multicenter study cannot be performed without proper funding, and therefore, we dare to doubt its feasibility. Due to logistical barriers, application of the study medication was not blinded in our study. However, the possibility of assessment bias was counteracted by the careful evaluation of several objective endpoints, including hemodynamic measurements and hard outcome parameters. According to the recommendations of the ASA, no sedation score was used to assess the level of sedation during the procedure [34]. Thus, sedation depth cannot be directly compared between randomized groups. As recommended by the same society, we undertook monitoring by pulse oximetry and blood pressure measurements at defined intervals as well as electrocardiographic assessment during the procedure. However, baseline arterial blood gas analysis providing information on PCO2 levels was available in only a minority of patients. Finally, this was a monocentric study performed in a high-output institution (1,800 bronchoscopies/year) which has considerable expertise with sedation for endoscopic procedures. Hence, caution might be needed when generalizing these results and introducing this sedative regimen to other institutions with a less experienced staff. The main strengths of the study comprise the random- ized, noninferiority design powered to detect even a small difference $(2 \%)$ in the mean lowest saturation between both randomized groups (conservative endpoint); the inclusion of both diagnostic and therapeutic procedures; the thoughtful documentation of hemodynamic and clinical parameters at diverse time points during the procedure and in the follow-up up to 28 days, and the inclusion of patient-centered outcomes (discomfort, cough and fear).

In conclusion, our data suggest that propofol given for sedation in medical thoracoscopy leads to a significantly higher incidence of hypoxemia and hypotension as compared to midazolam. Thus, in contrast to flexible bronchoscopy $[14-16,29]$ and as assessed by the surrogate marker hypoxemia, propofol should not be considered the first choice for sedation in medical thoracoscopy.

\section{Financial Disclosure and Conflicts of Interest}

Daiana Stolz was supported by grants from the Swiss National Foundation (PP00P3_128412/1). Additional funding was provided by the Clinic of Pulmonary Medicine and Respiratory Cell Research, University Hospital Basel.

None of the authors declare any conflict of interests.

\section{References}

1 Rodriguez-Panadero F, Janssen JP, Astoul P: Thoracoscopy: general overview and place in the diagnosis and management of pleural effusion. Eur Respir J 2006;28:409-422.

$\checkmark 2$ LoCicero J 2nd: Minimally invasive thoracic surgery, video-assisted thoracic surgery and thoracoscopy. Chest 1992;102:330-331.

3 Froudarakis ME: New challenges in medical thoracoscopy. Respiration 2011;82:197-200.

4 Rodriguez-Panadero F: Medical thoracoscopy. Respiration 2008;76:363-372.

5 Katlic MR, Facktor MA: Video-assisted thoracic surgery utilizing local anesthesia and sedation: 384 consecutive cases. Ann Thorac Surg 2010;90:240-245.

6 Danby CA, Adebonojo SA, Moritz DM: Video-assisted talc pleurodesis for malignant pleural effusions utilizing local anesthesia and I.V. sedation. Chest 1998;113:739-742.

7 Tschopp JM, Purek L, Frey JG, Schnyder JM, Diaper J, Cartier V, et al: Titrated sedation with propofol for medical thoracoscopy: a feasibility and safety study. Respiration 2011; 82:451-457.

8 Chen JS, Cheng YJ, Hung MH, Tseng YD, Chen KC, Lee YC: Nonintubated thoracoscopic lobectomy for lung cancer. Ann Surg 2011;254:1038-1043.
9 Rusch VW, Mountain C: Thoracoscopy under regional anesthesia for the diagnosis and management of pleural disease. Am J Surg 1987;154:274-278.

10 Gravino E, Griffo S, Gentile M, Storti M, Grossi N, Gily B: Comparison of two protocols of conscious analgosedation in video-assisted talc pleurodesis. Minerva Anestesiol 2005;71:157-165.

11 Chhajed PN, Kaegi B, Rajasekaran R, Tamm M: Detection of hypoventilation during thoracoscopy: combined cutaneous carbon dioxide tension and oximetry monitoring with a new digital sensor. Chest 2005; 127:585-588.

12 Bosslet GT, Devito ML, Lahm T, Sheski FD, Mathur PN: Nurse-administered propofol sedation: feasibility and safety in bronchoscopy. Respiration 2010;79:315-321.

13 Clarkson K, Power CK, O'Connell F, Pathmakanthan S, Burke CM: A comparative evaluation of propofol and midazolam as sedative agents in fiberoptic bronchoscopy. Chest 1993;104:1029-1031.

14 Stolz D, Kurer G, Meyer A, Chhajed PN, Pflimlin E, Strobel W, et al: Propofol versus combined sedation in flexible bronchoscopy: a randomised non-inferiority trial. Eur Respir J 2009;34:1024-1030.
15 Clark G, Licker M, Younossian AB, Soccal PM, Frey JG, Rochat T, et al: Titrated sedation with propofol or midazolam for flexible bronchoscopy: a randomised trial. Eur Respir J 2009;34:1277-1283.

16 Grendelmeier P, Kurer G, Pflimlin E, Tamm M, Stolz D: Feasibility and safety of propofol sedation in flexible bronchoscopy. Swiss Med Wkly 2011;141:w13248.

17 Pompeo E, Mineo D, Rogliani P, Sabato AF, Mineo TC: Feasibility and results of awake thoracoscopic resection of solitary pulmonary nodules. Ann Thorac Surg 2004;78: 1761-1768.

18 Pompeo E, Tacconi F, Mineo D, Mineo TC: The role of awake video-assisted thoracoscopic surgery in spontaneous pneumothorax. J Thorac Cardiovasc Surg 2007;133:786-790.

19 Peterson GN, Domino KB, Caplan RA, Posner KL, Lee LA, Cheney FW: Management of the difficult airway: a closed claims analysis. Anesthesiology 2005;103:33-39.

20 Caplan RA, Posner KL, Ward RJ, Cheney FW: Adverse respiratory events in anesthesia: a closed claims analysis. Anesthesiology 1990; $72: 828-833$.
Propofol vs. Midazolam in Medical Thoracoscopy 
21 Holm C, Christensen M, Rasmussen V, Schulze S, Rosenberg J: Hypoxaemia and myocardial ischaemia during colonoscopy. Scand J Gastroenterol 1998;33:769-772.

22 Johnston SD, McKenna A, Tham TC: Silent myocardial ischaemia during endoscopic retrograde cholangiopancreatography. Endoscopy 2003;35:1039-1042.

23 Seinela L, Reinikainen P, Ahvenainen J: Effect of upper gastrointestinal endoscopy on cardiopulmonary changes in very old patients. Arch Gerontol Geriatr 2003;37:25-32.

24 Deng L, Li CL, Ge SJ, Fang Y, Ji FH, Yang JP: STOP questionnaire to screen for hypoxemia in deep sedation for young and middle-aged colonoscopy. Dig Endosc 2012;24:255-258.

-25 Qadeer MA, Rocio Lopez A, Dumot JA, Vargo JJ: Risk factors for hypoxemia during ambulatory gastrointestinal endoscopy in ASA I-II patients. Dig Dis Sci 2009;54:1035-1040.
26 Ravaglia C, Gurioli C, Tomassetti S, Casoni GL, Romagnoli M, Gurioli C, et al: Is medical thoracoscopy efficient in the management of multiloculated and organized thoracic empyema? Respiration 2012;84:219-224.

27 Grundy S, Bentley A, Tschopp JM: Primary spontaneous pneumothorax: a diffuse disease of the pleura. Respiration 2012;83:185-189.

28 Grendelmeier P, Tamm M, Pflimlin E, Stolz D: Propofol sedation for flexible bronchoscopy: a randomised, noninferiority trial. Eur Respir J 2014;43:591-601.

29 Schlatter L, Pflimlin E, Fehrke B, Meyer A, Tamm M, Stolz D: Propofol versus propofol plus hydrocodone for flexible bronchoscopy: a randomised study. Eur Respir J 2011;38: 529-537.

30 Chow S-C, Shao J, Wang H: Sample Size Calculations in Clinical Research, ed 2. Boca Raton, Chapman \& Hall/CRC, 2008.
31 Stolz D, Chhajed PN, Leuppi JD, Brutsche M, Pflimlin E, Tamm M: Cough suppression during flexible bronchoscopy using combined sedation with midazolam and hydrocodone: a randomised, double blind, placebo controlled trial. Thorax 2004;59:773-776.

32 Lee P, Hsu A, Lo C, Colt HG: Prospective evaluation of flex-rigid pleuroscopy for indeterminate pleural effusion: accuracy, safety and outcome. Respirology 2007;12:881-886.

33 Hansen M, Faurschou P, Clementsen P: Medical thoracoscopy, results and complications in 146 patients: a retrospective study. Respir Med 1998;92:228-232.

34 American Society of Anesthesiologists Task Force on Sedation and Analgesia by Non-Anesthesiologists: Practice guidelines for sedation and analgesia by non-anesthesiologists. Anesthesiology 2002;96:1004-1017. 